Section Editor

John J. Millichap, MD

Paul McIntosh

Chafic Karam, MD

Correspondence to

Dr. Karam:

chafickaram@gmail.com

Clinical Reasoning:

\title{
A 38-year-old man with respiratory failure and progressive leg weakness
}

\section{SECTION 1}

A 38-year-old man developed hypoxemia following an elective right heart catheterization. He was being evaluated for pulmonary hypertension. The hypoxemia improved with oxygen supplementation, and the patient was admitted to the hospital for further workup and management. Overnight, following hospital admission, the patient became stuporous. Oxygen saturation was $98 \%$ on $3 \mathrm{~L}$ per minute nasal cannula; arterial blood gas $(\mathrm{ABG})$ revealed significant respiratory acidosis with $\mathrm{pH} 7.19$ and $\mathrm{CO}_{2}$ $>100 \mathrm{~mm} \mathrm{Hg}$. The patient was emergently intubated and mechanically ventilated. Chest $\mathrm{x}$-ray showed very low lung volumes. The patient improved and was extubated 2 days later. His pulmonary functioning test (PFT) values following extubation were $-50 \mathrm{~cm} \mathrm{H}_{2} \mathrm{O}$ negative inspiratory force (NIF) sitting up, $-45 \mathrm{~cm}$ $\mathrm{H}_{2} \mathrm{O}$ NIF lying flat, $1.10 \mathrm{~L}$ forced vital capacity (FVC) sitting up, and $0.95 \mathrm{~L} \mathrm{FVC} \mathrm{lying} \mathrm{flat.} \mathrm{The} \mathrm{etiology} \mathrm{to}$ both his pulmonary vascular disease and respiratory failure remained unclear, and at that time we evaluated the patient for neuromuscular causes of respiratory failure.

The patient claimed to be a stellar athlete in his younger days, but his functional status slowly declined over time. The patient first noticed weakness at age 27 years, when he realized he could no longer jump as high as before. He then began having trouble climbing stairs due to both hip weakness and shortness of breath. At age 30, he started having difficulty walking and would occasionally fall. At age 34 , he noticed shortness of breath when lying down to sleep at night. Now, at age 38 , he has trouble with balance, getting up from a chair, and occasional urinary incontinence. He takes narcotics for chronic back pain.

The patient denied chest pain, wheezing, pleurisy, leg pain, fever, chills, weight loss or gain, increased sputum production, nausea, vomiting, and diaphoresis. He also denied blood loss, melena, and tremors.

At the time of neurologic examination, the patient was unable stand and walk without assistance. Muscle strength testing using the Medical Research Council scale graded right/left showed shoulder abduction $4 / 4$, hip flexion $2 / 2$, knee extension $3 / 3$, and knee flexion $3 / 3$. The deep tendon reflexes at the biceps, triceps, brachioradialis, knee, and ankle were $2+$ bilaterally. The rest of the examination, including the sensory examination, was normal.

\section{Questions for consideration:}

1. What is the differential diagnosis for hypercapnic respiratory failure and muscle weakness?

2. Where do the neurologic deficits localize? 


\section{SECTION 2}

Hypercapnic respiratory failure can be caused by medical conditions, neurologic conditions, or both. It can also be precipitated iatrogenically by treating some patients' lung disease with nasal oxygen, which can suppress the respiratory drive.

In general, medical causes of hypercapnic respiratory failure are ruled out quickly by assessing response to nasal $\mathrm{O}_{2}$, PFTs, ABG, and chest imaging.

Neurologic conditions that cause hypercapnic respiratory failure can be divided into central and peripheral disorders. Central causes can result from structural lesions (e.g., brainstem tumor) or toxic metabolic states (e.g., narcotic overdose), whereas neuromuscular conditions are classified as peripheral. In neuromuscular disease, the respiratory rate is usually increased and breathing is shallow while in central causes the respiratory rate is decreased, erratic, or both.

Neuromuscular conditions that can cause hypercapnic respiratory failure in adults are listed in the table. Those can be classified into diseases that affect the anterior horn cells, the roots and nerves, the neuromuscular junction, and myopathies. The proximal weakness on examination with preservation of sensation and reflexes is suggestive of a myopathy. Given the localization, an inherited myopathy is the most probable diagnosis in the setting of the slowly progressive and nonfluctuating proximal weakness. Of the inherited myopathies, Pompe disease, limbgirdle muscular dystrophy 2I (LGMD2I), hereditary myopathy with early respiratory failure (HMERF), myotilinopathy, and occasionally limb-girdle muscular
Table Neuromuscular causes of hypercapnic respiratory failure

$\begin{array}{ll}\begin{array}{l}\text { Location of effect } \\ \text { Anterior horn cells }\end{array} & \begin{array}{l}\text { Associated diseases } \\ \text { ALS and other motor neuron } \\ \text { diseases, polio, polio-like viruses } \\ \text { (e.g., West Nile virus) }\end{array} \\ \begin{array}{l}\text { Radiculoneuropathy } \\ \text { Neuropathy }\end{array} & \begin{array}{l}\text { GBS, CIDP } \\ \text { CMT, PTS with phrenic nerve } \\ \text { involvement, CIP, infections, toxins }\end{array} \\ \begin{array}{l}\text { Neuromuscular } \\ \text { junction }\end{array} & \text { MG, botulism } \\ \text { Muscle } & \begin{array}{l}\text { Dystrophinopathies, DM, LGMD, } \\ \text { Pompe disease, CIM, inflammatory } \\ \text { myopathies, HMERF }\end{array}\end{array}$

Abbreviations: ALS = amyotrophic lateral sclerosis; CIDP = chronic inflammatory demyelinating polyneuropathy; $\mathrm{CIM}=$ critical illness myopathy; CIP = critical illness polyneuropathy; $\mathrm{CMT}=$ Charcot-Marie-Tooth; DM = myotonic dystrophy; GBS = Guillain-Barré syndrome; HMERF = hereditary myopathy with early respiratory failure; LGMD = limb-girdle muscular dystrophy; PTS = Parsonage-Turner syndrome.

dystrophy $2 \mathrm{~A}$ and limb-girdle muscular dystrophy $2 \mathrm{C}-2 \mathrm{~F}$ can all produce proximal weakness and respiratory failure. HMERF, Pompe, and LGMD2I are more likely to involve respiratory failure when the patient is still ambulatory compared to the others. Other inherited muscle diseases can also cause respiratory failure but this usually happens at the end stage of the disease.

\section{Question for consideration:}

1. What investigations should be included in the general neuromuscular workup? 


\section{SECTION 3}

Prior to hospitalization, the patient was evaluated by both physical medicine \& rehabilitation and general neurology as an outpatient. Workup consisting of brain, cervical, and thoracic MRI were negative. The only notable laboratory results were an elevation of aspartate aminotransferase (AST) (144 U/L), alanine aminotransferase (ALT) (131 U/L), and creatine kinase (CK) (917 IU/L).

The patient's AST and ALT continued to be elevated in the low 100s; however, the gamma GT level was normal, suggesting that the elevated AST and ALT were of muscular origin. The patient had mildly elevated CK ( $375 \mathrm{U} / \mathrm{L}$; less than the value 4 weeks prior of $971 \mathrm{U} / \mathrm{L}$ ).
Nerve conduction studies were normal. Needle EMG showed fibrillation potentials and myotonia in the iliopsoas and thoracic paraspinal muscles. Motor unit potentials had small amplitude, short duration, polyphasic morphology, and increased recruitment suggestive of an irritative myopathy with myotonia, predominantly affecting the proximal legs.

\section{Question for consideration:}

1. Based on the clinical information and abnormal EMG, what more targeted workup should be conducted to establish a diagnosis? 


\section{SECTION 4}

A dried blood spot enzyme assay for acid maltase was $2.40 \mathrm{pmol} / \mathrm{punch} / \mathrm{h}$, below the reference of $>3.88$. A muscle biopsy was performed showing extensive vacuolization of both fiber types with variation in fiber size. There was increased periodic acid-Schiff staining consistent with glycogen deposits (figure). Genetic testing for Pompe disease showed 2 heterozygous mutations in the $G A A$ gene. In retrospect, review of the spine MRI showed atrophy and fatty replacement of paraspinal muscles.

Late-onset Pompe disease is a diagnostic challenge due to its heterogeneous clinical picture and its nonspecific myopathic symptomatology including muscle weakness, pain, cramps, generalized fatigue, and shortness of breath. The differential diagnosis includes other muscular dystrophies, congenital myopathies, inflammatory myopathies, metabolic myopathies, motor neuron disorders, and neuromuscular junction disorders. The average delay in diagnosis is 10 years, typically due to misdiagnosis or lack of awareness for the adult form of the disease. Prompt diagnosis of Pompe disease is critical because there is a treatment available: enzyme replacement therapy (ERT).

DISCUSSION Pompe disease is an autosomal recessive metabolic myopathy caused by the deficiency of the lysosomal enzyme acid $\alpha$-glucosidase (acid maltase). ${ }^{1}$ The disease is characterized by progressive

\section{Figure Muscle biopsy}
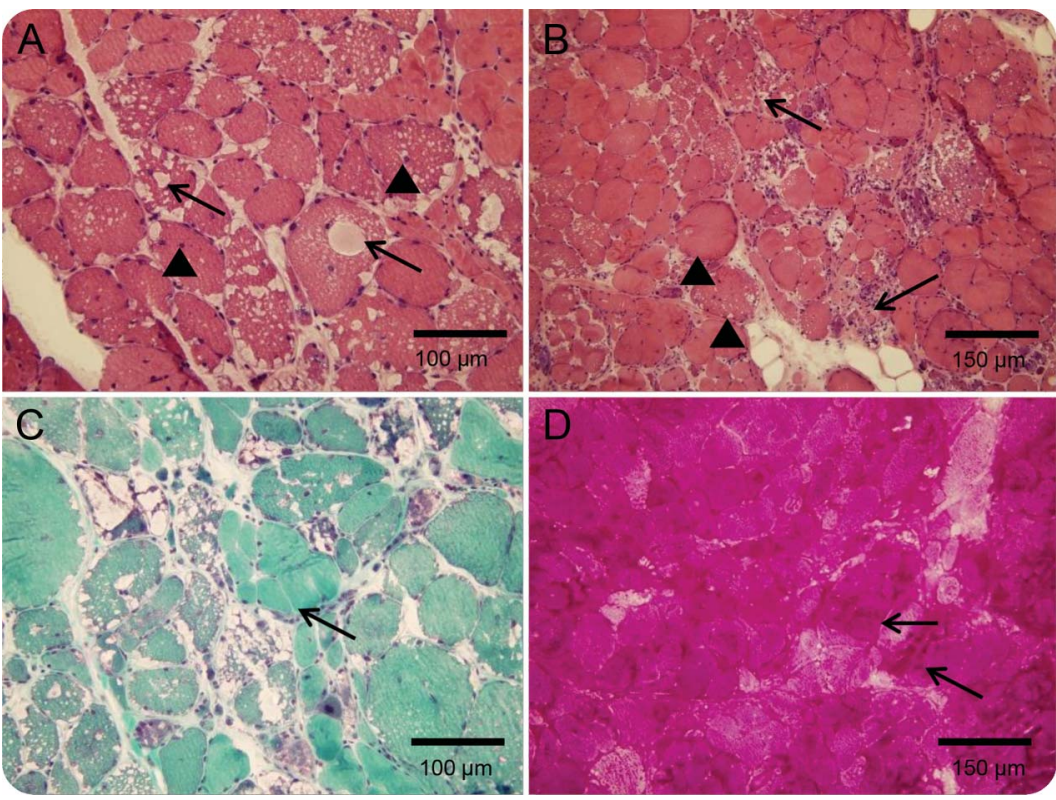

(A) High-power hematoxylin \& eosin (H\&E) stain shows diffuse vacuolization (arrows) and centralized nuclei (arrowheads). (B) Lower power H\&E stain demonstrates both atrophied (arrows) and hypertrophied fibers (arrowheads) and also shows thickened interstitial stroma. (C) Trichrome stain shows severely affected fibers with extensive vacuolization and other minimally affected fibers (arrow). (D) Periodic acid-Schiff stain highlights the extensive glycogen accumulation (arrows). proximal limb-girdle weakness, affecting the lower extremities more than the upper extremities. The weakness is most pronounced in the pelvic girdle musculature, particularly the hip flexors. Trunk extensors and abdominal muscles are typically affected as well. ${ }^{2}$ Exercise intolerance, difficulty climbing stairs, and frequent falling are common initial clinical complaints. ${ }^{3}$ Pompe disease can also affect the diaphragm, resulting in exertional dyspnea and orthopnea. People with Pompe disease may have morning headaches due to inadequate ventilation while lying supine overnight, and bilevel positive airway pressure is commonly needed as the disease progresses. Interestingly, there is a weak relationship between diaphragm strength and limb-girdle muscle strength in Pompe disease; therefore, respiratory failure may occur before other overt signs of muscle weakness. ${ }^{4}$ Fatigue, lower back pain, and neck pain are also seen in Pompe disease. Ptosis and other issues such as incontinence can occur as well.

Some clues to the diagnosis of late-onset Pompe disease are an elevated AST, ALT, and CK in the presence of proximal lower extremity muscle weakness, particularly if there is unexplained respiratory insufficiency. ${ }^{5}$ EMG is a useful diagnostic tool, but in some cases of Pompe disease the only electrical abnormality (myotonic discharges) is within the lower paraspinals, which is nearly pathognomonic. ${ }^{6}$ Muscle biopsy is helpful but not required for the diagnosis, as the sensitivity is low. ${ }^{7}$ GAA activity testing can be performed on dried blood spots as a screening test. The gold standard for diagnosis (i.e., confirmatory test) is GAA activity testing in fibroblasts or muscle or $G A A$ gene sequencing. ${ }^{8}$

The patient in this case study is now on ERT with the hope of slowing the progression of the disease. The Late-Onset Treatment Study and its extension trial concluded that the treatment of Pompe disease with ERT was associated with improved walking distance and stabilization of pulmonary function over an 18-month period when compared to baseline. ${ }^{9}$ Thus, ERT may affect the natural history of this progressive and degenerative disease. Therefore it is essential that any patient with Pompe disease be recognized and diagnosed quickly. Because dry blood spot testing is relatively inexpensive, easy to obtain, and powerful at clinching a diagnosis, it should be employed early in the diagnostic course as a screening tool when Pompe disease is on the differential. ${ }^{10}$

\section{AUTHOR CONTRIBUTIONS}

P. McIntosh: acquisition of information, research for and writing of the manuscript. Dr. Karam: critical revision of manuscript for important intellectual content.

\section{STUDY FUNDING}

No targeted funding reported. 


\section{DISCLOSURE}

P. McIntosh reports no disclosures relevant to the manuscript. C. Karam serves as Neurology ${ }^{\circledR}$ WriteClick ${ }^{\circledR}$ deputy editor and received speaker honoraria from Nufactor and consulting honoraria from Lundbeck. Go to Neurology.org for full disclosures.

\section{REFERENCES}

1. Hers HG. Alpha-glucosidase deficiency in generalized glycogen storage disease (Pompe's disease). Biochem J 1963; 86:11-16.

2. Case LE, Kishnani PS. Physical therapy management of Pompe disease. Genet Med 2006;8:318-327.

3. Hagemans ML, Winkel LP, Van Doorn PA, et al. Clinical manifestation and natural course of late-onset Pompe's disease in 54 Dutch patients. Brain 2005;128: 671-677.

4. Pellegrini N, Laforet P, Orlikowsi D, et al. Respiratory insufficiency and limb muscle weakness in adults with Pompe's disease. Respir J 2005;26:1024-1031.
5. Mellies U, Lofaso F. Pompe disease: a neuromuscular disease with respiratory muscle involvement. Respir Med 2009; 103:477-484.

6. Papsdorf TB, Howard JF, Chahin N. Pearls \& Oy-sters: clues to the diagnosis of adult-onset acid maltase deficiency. Neurology 2014;82:73-75.

7. Vissing J, Lukacs Z, Straub V. Diagnosis of Pompe disease: muscle biopsy vs blood-based assays. JAMA Neurol 2013;70:923-927.

8. Kishnani PS, Steiner RD, Bali D, et al. Pompe disease diagnosis and management guideline. Genet Med 2006;8:267-288.

9. van der Ploeg AT, Barohn R, Carlson L, et al. Open-label extension study following the Late-Onset Treatment Study (LOTS) of alglucosidase alfa. Mol Genet Metab 2012;107:456-461.

10. Goldstein JL, Young SP, Changela M, et al. Screening for Pompe disease using a rapid dried blood spot method: experience of a clinical diagnostic laboratory. Muscle Nerve 2009;40:32-36. 


\section{Neurology}

\section{Clinical Reasoning: A 38-year-old man with respiratory failure and progressive leg weakness}

Paul McIntosh and Chafic Karam

Neurology 2016;86;e190-e194

DOI 10.1212/WNL.0000000000002634

\section{This information is current as of May 2, 2016}

\section{Updated Information \& Services}

References

Subspecialty Collections

Permissions \& Licensing

Reprints including high resolution figures, can be found at: http://n.neurology.org/content/86/18/e190.full

This article cites 10 articles, 1 of which you can access for free at: http://n.neurology.org/content/86/18/e190.full\#ref-list-1

This article, along with others on similar topics, appears in the following collection(s):

All Clinical Neurology

http://n.neurology.org/cgi/collection/all_clinical_neurology All Neuromuscular Disease

http://n.neurology.org/cgi/collection/all_neuromuscular_disease Muscle disease

http://n.neurology.org/cgi/collection/muscle_disease

Information about reproducing this article in parts (figures,tables) or in its entirety can be found online at:

http://www.neurology.org/about/about_the_journal\#permissions

Information about ordering reprints can be found online:

http://n.neurology.org/subscribers/advertise

Neurology ${ }^{\circledR}$ is the official journal of the American Academy of Neurology. Published continuously since 1951, it is now a weekly with 48 issues per year. Copyright @ 2016 American Academy of Neurology. All rights reserved. Print ISSN: 0028-3878. Online ISSN: 1526-632X.

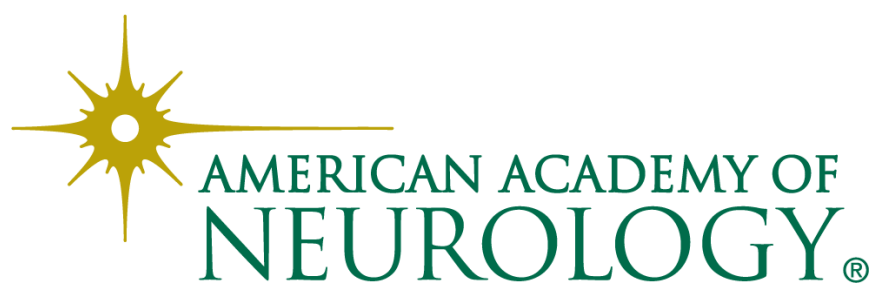

